\title{
Characterization and kinetic study of Ibuprofen Biodegradation by native bacterial Citrobacter strains PPYI-2 and YPI-2
}

Dharmender Kumar ( $\nabla$ dkbiology@gmail.com)

Deenbandhu Chhotu Ram University of Science and Technology https://orcid.org/0000-0001-5074-2369

Sunil Chopra

Deenbandhu Chhotu Ram University of Science and Technology

\section{Research Article}

Keywords: Ibuprofen, Design Expert ${ }^{\circledR}$, Wastewater, Batch culture, Gas chromatography-Mass spectroscopy (GC-MS)

Posted Date: February 7th, 2022

DOI: https://doi.org/10.21203/rs.3.rs-1306737/v1

License: () (7) This work is licensed under a Creative Commons Attribution 4.0 International License. Read Full License 


\section{Abstract}

Ibuprofen (IBU) is the third most used drug in the world. This enters our water system due to human excretion discharge. Thus, it attracts the attention of environmentalists for their environmental fate and degradation behavior. In the present study, the two IBU degrading Citrobacter freundii strain PYI-2 (MT039504) and Citrobacter portucalensis strain YPI-2 (MN744335) was isolated using enrichment culture technique, identified, and characterized from industrial wastewater samples. Their physiological and batch culture degradation studies have indicated that these strains involved in IBU degradation and their intermediates produced during were analyzed. These strains degrade IBU in the batch culture. The Design Expert ${ }^{\circledR}$ software suggested the optimum pH conditions for the growth of PYI2 and YPI2 were 6.9 and 5.8 and the optimum temperatures were, $42^{\circ} \mathrm{C}$ and $32^{\circ} \mathrm{C}$, respectively. This was also seen during experimental study. After degradation, the GC-MS analysis of the chromatogram peaks indicated that hydroxyibuprofen, 2- (4-hydroxyphenyl-) propionic acid, 1,4-hydroquinone, and 2-hydroxy-1,4-quinol intermediate compounds were identified, with the retention time of 14.987, 15.654, 11.765, and 10.827, respectively. Finally, on the basis of analysis of GC-MS data, the metabolic pathway for degradation was predicted by Pathpred (online tool), and other research data available for the degradation of IBU. Therefore, these strains have shown the potential for the degradation of IBU and they can be deployed for further use in the bioremediation program.

\section{Introduction}

Water is an important part of the living system, but, the purity of the drinking water is deteriorating (Peters and Meybeck 2000). The main reason for deterioration is the entry of pollutants into water sources, due to manmade activity and industrialization. These pollutants are a mixture of different compounds such as pesticides, industrial chemicals, pharmaceuticals, personal care products (PPCP), artificial hormones, plastic waste, and pharmaceuticals, etc. (Deblonde et al. 2011). PPCPs are fast-growing organic contaminants that include a variety of chemicals such as; pharmaceuticals, antibiotics, hormones, non-steroidal anti-inflammatory drugs (NSAIDs), etc. (Fent et al. 2006; Farré et al. 2008; Barbosa et al., 2016). They enter into the aquatic environment due to relese from household waste and sewage treatment plants. The wastewater present in the treatment plants consists of household wastewater with small and medium-sized industrial waste, agricultural waste, hospital wastewater, etc. They also contain human and animal excreta (Jurado et al. 2012). In some cases, around $60-95 \%$ of the active ingredients such as NSAIDs, drugs, medications, etc. are released. We use a large number of PPCPs and we know almost all PPCPs are active. Currently, the highest environmental protection organization, the United States Environmental Protection Agency (USEPA), considers PPCPs as the emerging pollutant. On their entry into the ecosystem, these pollutants have a great impact on human health after. In recent decades the PPCPs have been detected in rivers, lakes, estuaries, deltas, seas, oceans, etc., (Ellis 2006). But, the critical analysis of NSAID degrading efficiency, pathways, and bacterial degrading mechanisms is limited, and still results indicated that some bacterial strains have the potential to reduce NSAIDs (Rastogi et al. 2021).

Ibuprofen (IBU) is (RS) -2- (4- (2-methyl propyl) phenyl) propanoic acid is the third most popular, recommended, and most used drug (Marchlewicz et al. 2015). This is why it is often discovered in various environmental resources. Studies in various countries have shown that its high consumption leads to a release of its metabolite from $\mu \mathrm{g}$ per liter concentration in the environment (Daughton and Ternes 1999; Onesios et al. 2009). Its concentration in sewage wastewater ranges from $11 \mu \mathrm{g} /$ I to over $100 \mathrm{mg} / \mathrm{L}$, while less than $1 \mu \mathrm{g} /$ I was found in groundwater(Murray et al. 2010; Pal et al. 2010; Santos et al. 2010). It can also alter the growth and fertility of aquatic organisms, even present in the concentration of $\mathrm{ng} / \mathrm{L}$. It also causes genotoxic effects on fishes(Murray et al. 2010; Pal et al. 2010; Santos et al. 2010). However, partial elimination of IBU from wastewater treatment plants was reported in many studies under different physical conditions, concentrations, growth factors, etc. (Daughton and Ternes 1999; Pal et al. 2010; Santos et al. 2010). But, there is a need to examine and predict the models that influence the degradation in wastewater treatment. There is a need for a suitable mathematical model that can predict the removal of such pollutants. Several models was proposed for biodegradation which follows the first order of kinetics of drug compounds (Joss et al. 2006). Moreover, many contaminants were removed by photocatalysis, ozonation, activated carbon adsorption, and ultrasonic oxidation, but IBU was not removed (Murdoch and Hay 2015). Biodegradation techniques are the more cheap, more stable, and environmentfriendly approach for the removal of such pollutants (Sharma et al. 2019). IBU makes entery into different water bodies, pretends health risk to living organisms and acts as a contaminant of emerging concern (Chopra and Kumar (2020a).

The other studies indicated that pure strains was reported, that can degrade IBU such as; Nocardia sp. NRRL 5646, Variovorax Ibu-1, Sphingomonas Ibu-2, Bacillus thuringiensis B1(2015b), Patulibacter sp. 111 etc. (Chen and Rosazza 1994; Li and Rosazza 1997; Murdoch and Hay 2005a, 2013; Almeida et al. 2013; Marchlewicz et al. 2017a). While Marco-Urrea (Marco-Urrea et al. 2010a) 2010 identified the fungal strain which can degrade it. IBU was degraded by Patulibactersp. 111 in the presence of tryptone and yeast extract. This suggest that acyl-CoA synthetase iron-sulfur cluster and enoyl-CoA enzymes were involved during degradation (Almeida et al. 2013). While in another study N. NRRL 5646 strain degraded it into Ibuprofenol acetate and Ibuprofenol (Chen and Rosazza 1994). Its degradation pathway was reported in S.Ibu-2 and V. Ibu-1 strains (Murdoch and Hay 2005a, 2013). The degradation of IBU by V.Ibu-1 has shown the involvement of the meta ring fission enzymes (Murdoch and Hay 2015).

Thus, this study was focused on isolating bacterial strains, which has the capability to degrade IBU from wastewater samples by enrichment techniques. For the degradation study IBU was used as the sole carbon and energy source substrate. Optimization experiments wase performed using Design Expert ${ }^{\circledR}$. Bacteria that degrade IBU harvested and their kinetics analyzed using Haldane growth model and results of batch culture degradation study interpreated. Morphological and physiological tests was performed in order to characterize the phenotypic and genotypic features of the strain. Further, 16S rRNA sequencing was to identify strains up species level. Finally, degradation intermediate metabolites was identified through GC-MS, and PathPred and degradation pathway proposed.

\section{Materials And Methods}

\section{Chemicals used and sample collection}


Ibuprofen (IBU, 99\% pure; Sigma Aldrich, USA) and all other technical grade and molecular grades chemicals. Pulp and paper industry waste and industrial wastewater samples, was collected from Yamunanagar, Haryana, India. These sample collection sites having untreated sewage discharge, small and mediumsized industrial discharges, and submerged solid wastes etc. Samples were collected in sterile containers and brought to the laboratory in refrigerated containers. Besides, these samples was stored in the refrigerator at $4^{\circ} \mathrm{C}$, until further processing done. Immediately, before use, unwanted contaminants from the samples was removed by sedimentation.

\section{Enrichment culture, isolation, screening, and selection of IBU degrading bacteria}

The initial degradation experiments was conducted in $250 \mathrm{ml}$ conical flasks with Bushnell-Haas (BHM) medium (HiMedia Mumbai, India), supplemented with $5 \mathrm{mg} / \mathrm{L}$ of IBU (as sole carbon and energy source). The N/10 of the samples added into the flasks and these flasks was incubated in a shaker at $37^{\circ} \mathrm{C}$ and $150 \mathrm{rpm}$ (including negative control without wastewater sample and positive test control with autoclaved active sample). Further, 5 mg / L of IBU was added into flasks with an interval of 10 days. After that, bacterial screening was performed. The serial dilution was performed in distilled water up to $10^{-5}$ dilutions. Later, these dilutions were spread on to the petri plate containing agar, BHM, and $5 \mathrm{mg} / \mathrm{L}$ of IBU. Further, these plates were incubated at $37^{\circ} \mathrm{C} / 24 \mathrm{~h}$ (Norris and Ribbons 1972).

After 24 hours, the plates showing colony were further analyzed by for colony counting. The selected bacterial colonies were further grown on nutrient agar (NA) plates and incubated at $37^{\circ} \mathrm{C}$ for $24 \mathrm{~h}$. This process of serial dilution was repeated until the pure bacterial colony was obtained. Finally, pure bacterial isolates were stored in glycerol stocks at $-80^{\circ} \mathrm{C}$ for further use (Swift 1921). Further, IBU degrading bacteria were grown on MSM agar plates supplemented with increasingconcentration of IBU (initial $2 \mathrm{mg} / \mathrm{L}$ and gradually increased to $20 \mathrm{mg} / \mathrm{L}$ ). The final concentration step was until the bacteria survived. All experiments were performed at $37^{\circ} \mathrm{C}$. Finally, the best degrading bacterial colonies were selected for further study (Norris and Ribbons 1972).

The IBU degradation in the samples was detected with the UV spectrophotometer at $\mathrm{OD}_{265}($ Kesur et al. 2012). The degradation percentage (R), was calculated as per

Eq. 1:

$$
\mathrm{R}=\frac{C_{0}-C_{t}}{C_{0}} \times 100
$$

1

Here, ' $C_{O}$ is the absorbance at initial concentration of IBU; ' $C t$ ' is the absorbance after incubation at the time ' $t$ '.

\section{Identification and molecular characterization of IBU degrading strains}

Further, the IBU degrading stains was characterized through their; morphological analysis, biochemical characterization, and molecular identification for species analysis. 24h old grown bacterial culture was used for these characterization study. Gram's staining was performed for morphological characterization of strains by standard protocol (Hucker and Conn 1923). The biochemical tests were performed by using the KB013 identification kit (Gorashi et al. 2014). The biochemical characterization was performed according to the standard protocol.

The $24 \mathrm{~h}$ old bacterial growth culture of thease strains was used for the isolation of genomic DNA using the standard alkaline lysis method (Wilson 2001) and further molecular characterization was done. from. The $1 \mathrm{ml}$ of the bacterial culture was takenin the micro-centrifuge tube. After centrifugation was done at $10000 \mathrm{rpm}$ for $5 \mathrm{~min}$ and the supernatants discarded and pallets were taken for further use. Thepellet washed with distilled water, cell lysis solution was added to tubes and tubes were incubated at $37^{\circ} \mathrm{C}$ for $30 \mathrm{~min}$. The micro-tube filters was used to filter the DNA recovered after the centrifugation of the sample at $10000 \mathrm{rpm}$ for $5 \mathrm{~min}$. Later, the DNA was washed with ethanol and an elution buffer was added. Further, DNA was stored at $-20^{\circ} \mathrm{C}$ until further use (Smith et al. 2003). The gel electrophoresis was performed for qualitative analysis of isolated DNA (Aaij and Borst 1972). For the species characterization, the DNA of isolated strains was amplified with polymerase chain reaction (PCR) with16S rRNA universal primers viz. 27F 5'(AGAGTTTGATCMTGGCTCAG)3' and 1492R 5'(CGGTTACCTTGTTACGACTT)3' primers (Chandra et al. 2006). Further, 16S rRNA sequencing was performed (Eurofins Genomics India Pvt. Ltd.) with 27F and 1492R primers (Wallis and Morrell 2011).

After 16S rRNA sequencing,the sequence of bacteria of approximately $1500 \mathrm{bp}$ was generated and this sequence was further used for BLAST analysis on the BLAST platform of NCBI (https://blast.ncbi.nlm.nih.gov/Blast.cgi) (Ashton et al. 1997). Also, the evolutionary history of the strains was determined by neighborhood (NJ) method. Further, the phylogenetic analysis was performed with MEGA7 software (Kumar S et al. 2016). The Clustal-W program was used to determine the exact taxonomic position of the sequences (Thompson et al. 1994). Thereafter, the percentage of replicating trees in the phylogenetic tree was determined by linking the clustered taxa and the bootstrap test (with500 replicates) (Felsenstein 1985). Sequence evolutionary distances were calculated by the Kimura 2-parameter method which determines the number of base substitutions/ site (Kimura 1980).

\section{Optimization of IBU degrading bacteria}

The Design-Expert ${ }^{\circledR}$ software (ver. DX 12.0.1, Stat-Ease, Minneapolis, USA) was used(Alben 2002) to know the optimal physical conditions reported for the degradation of IBU by the strains PYI2, and YPI2. The parameters such as temperature, $\mathrm{pH}$, shaking speed, and concentration of IBU were designated. After 
that, the designing of the experiments was done. The initial and final values were inserted in the Box-Behnken design (BBD) model (Muthukumar et al. 2003). The parameters $\mathrm{A}, \mathrm{B}, \mathrm{C}$, and $\mathrm{D}$ were allocated to $\mathrm{pH}$, temperature, agitation speed, and concentration of IBU, respectively. The initial value of $\mathrm{A}, \mathrm{B}, \mathrm{C}$, and degree of freedom (DOF) was $5,10^{\circ} \mathrm{C}, 80 \mathrm{rpm}$, and $0.5 \mathrm{mg} / \mathrm{L}$ with thereo final value of $9,60^{\circ} \mathrm{C}, 250 \mathrm{rpm}$, and $30 \mathrm{mg} / \mathrm{L}$ respectively. Further, these values subjected to BBD model and software suggested a matrix. The experiments were performed in the $250 \mathrm{ml}$ flasks with the same physical conditions. . After inserting the parameters, the response was used to determine the biodegradation (\%) of IBU. The degradation values of IBU were entered into the models (Jahanshahi et al. 2008).

Subsequently, the statistical analysis was performed with analysis of variance (ANOVA) and multiple regression used to identify the best-fit response by the BBD quadratic model. Also, this data was used to identify various statistical parameters viz. such as F-value, coefficient of variation (CV), degree of freedom (DF), regression coefficient $\left(R^{2}\right)$, and the sum of square. The equations based on real factors was generated by the software. After that, the normal contour plots was compared with remaining contour plots based on the expected value. The report is generated and this was further analyzed with the predicted values. After that, the contour diagrams, single factor diagrams, predicted $v s$. real world diagrams, and compatible response surface methodologies (RSM) plots (also known as 3-D diagrams) were generated. These 3D graphs were used to identify the effect of various physical factors and the optimal parameters for IBU degradation (Wang et al. 2017).

\section{Kinetic study of IBU degrading strains}

To study the kinetic analysis of IBU degrading isolates, the $250 \mathrm{ml}$ conical flasks containing BHM supplemented with IBU used. Further, the sterilized BHM containing IBUo study was performed in batch culture based on optimum physical parameters. The IBU ( 1 to $50 \mathrm{mg} / \mathrm{L}$ ) was used for kinetic analysis of individual strains for the degradation of IBU The degrading mixtures was e withdrawn from the conical flask after the $4 \mathrm{~h}$ to $8 \mathrm{~h}$, interval of time. The isolated strains were seen in the nutrient broth (NB) and further, incubated at $37^{\circ} \mathrm{C}$ for $24 \mathrm{~h}$. The cell growth was measured by using a UV-vis- spectrophotometer at $\mathrm{UV}_{600}$. After 15 days the dry biomass of individual strain was recovered through a filter $\left(0.2-\mu \mathrm{m}\right.$-pore) and then it was further dried for $24 \mathrm{~h}$ at $80^{\circ} \mathrm{C}$ in a hot air oven (Panikov 1995). Later plots were made between concentration vs. reaction time for IBU degradation. The experimental data of biodegradation of IBU were put in Haldane's growth kinetics model(Halden et al. 1997) (modified version of the Monod kinetics model) for the analysis of best fit (Origin 2017, software) (Deschenes and of Texas 2000). Haldane's growth model kinetic analysis Eq. 2:

$$
\mu=\mu_{\max } \frac{\mathrm{S}}{\mathrm{K}_{\mathrm{S}}+\mathrm{S}+\left(\frac{\mathrm{S}_{2}}{\mathrm{~K}_{\mathrm{i}}}\right)}
$$

2

Here, ' $\mu$ ' is the specific growth rate of individual strain; $\mu$ max is the maximum specific growth rate of strain after time ' $t$; ' $S$ ' is the amount of IBU (mg/L); ' $K s^{\prime}$ is half-saturation constant $(\mathrm{mg} / \mathrm{L})$ and ' $K$ ' is inhibition constant $(\mathrm{mg} / \mathrm{L})$.

Further, yield coefficient of the individual strain and linear regression were used by accessing Eq. 3:

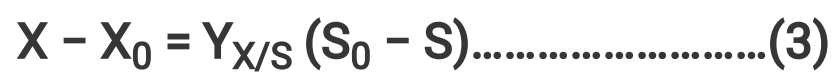

where ' $X$ and ' $X 0^{\prime}$ ' are the biomass of strain S1 at the time ' $t$ ' and the initial amount of biomass strain S1 (mg/L), and ' $S$ and 'SO' are the IBU concentration after time ' $t$ ' and an initial amount of IBU (mg/L), respectively.

\section{Identification of metabolites and pathway prediction for the IBU degrading strains}

To identify the intermediates produced during the biodegradation of IBU. The $5 \mathrm{ml}$ of degrading samples were withdrawn from the conical flasks inoculated with strain PYI2, and YPI2 .After 15 days of completing the experimental degrading experiment, the degrading sample was filtered with filter paper with a pore size of $0.2-\mu \mathrm{m}$. The filtrate was further centrifuged at 16,000 $\mathrm{xg}$ for $1 \mathrm{~min}$. The supernatant was then transferred to a fresh tube and another $1: 1 \mathrm{v} / \mathrm{v}$ of ethyl acetate. The mixtures were then mixed and kept in a resting position for $24 \mathrm{~h}$. Afterwards two layers of supernantant and pelletwere form and supernantant (top layer) was taken for further analysis and pellet discared.

Gas-chromatography mass- spectrometry (GC-MS) used to identify degrading metabolites. Ethyl acetate sample was used for running GC-MS (Shimadzu-QP2010) along with the T-20 GC-MS thermal desorption system. In order to to perform GC-MS, the electronic impact pattern was set at 70 eV. Then, the helium gas injection (He; $99.9 \%$ ) was stopped at a volume of $0.1 \mathrm{ml} / \mathrm{min}$ at $250^{\circ} \mathrm{C}$ with cleavage of $10: 1$. Then, the source temperature, the ions and the quadrupole temperature were adjusted to $280^{\circ} \mathrm{C}$ and $150^{\circ} \mathrm{C}$,. In addition to this, the GC-MS tool was equipped with fragments of 40 to $550 \mathrm{Da}$ at $0.5 \mathrm{intervals}$ of $70 \mathrm{eV}$ spectra at $280^{\circ} \mathrm{C}$ for 9 minutes. After setting the instrument, as above, the sample has been poured into GC-MS vials and placed in the automatic sample loading tray (Jardim et al. 1997). After loading the samples, the above program has been executed. After the final test, the chromatograph was developed and the time incresases. Each peak in the graph represents the specific compounds. Besides, the peaks of the mass spectrum were generated using available commercial prepared libraries (Willy Library, Drug Library, etc.). These peaks in their retention time was compared to available literature and online information on these compounds (Hoffmann et al. 1989). After this the query was subjected to PathPred (a free online tool) analysis. The KEGG server (Kyoto

Page $4 / 12$ 
Encyclopedia of Genes and Genomes (https://www.genome.jp/tools/pathpred/) has compared the available path to the database and predicted the various degradation pathway for IBU (Ogata et al. 1998).

\section{Results And Discussion}

\section{Enrichment culture, isolation, screening, and selection of IBU degrading bacteria}

The main objectives behind this study was for the characterization bacteria with the potential to degrade IBU. The experiments was conducted with the collection of samples and enriched with IBU in shake flask study. During initial degradation no visible changes was appeared in conical flasks containing IBU. The 5 colonies of IBU degrading bacteria were seen on BHM agar plates supplemented with IBU. The tolerance of the individual strain at the amount of IBU. Out of 5 microbial colonies, 3 colonies were isolated from wastewater industry samples of Yamunanagar site, while two strains were observed from paper and pulp industry waste Yamunanagar India, samples. Out of these 5 strains only 2 strains has shown the tolerance of $8 \mathrm{mg} / \mathrm{L}$ of IBU.

\section{Identification and molecular characterization of IBU degrading strains}

The isolated strains recovered from enrichment culture were the true degrading strains and they were further characterized via morphological, microscopic examining based on Gram's staining test, biochemical tests, and molecular aracterization based on 16S rRNA sequencing. The degrading isolates was coded as PYI2 and YPI2. The isolate PYI2 found was Gram-positive and YPI2 Gram-negative. Both the strains had rod-shaped structure but a cocci structure observed to isolate PYI2. On biochemical characterization with malonate test conducted with KB013 kit. The negative reaction seen in PYI2, and YPI2 for the malonate and Voges-Proskauer test while all other results were positive, except for arginine which has shown variable reaction for both of these strains (Table 1).

The DNA extracted from PYI2, and YPI2 bacterial isolates by alkaline lysis method and gel electrophoresis was performed. After running the DNA through electrophoresis, there was a single band detected. Later the amplification of genomic DNA was done with universal (27F and 1492R) primers and standard protocols was followed for the PCR. Afterwards, the PCR products were again run on agarose gel electrophoresis, which resulted in a single band of almost $1500 \mathrm{bp}$. The PCR product was purified and sent to Eurofins Genomics India Pvt. Ltd. for sequencing. The Sangar's DNA sequencing method used to perform sequencing of the strain, and from this sequence t the chimera was detected by DECIPHER online tool (DECIPHER v11.9: http://www.deciphergenomics.org). There was no chimera was detected in this sequencs. Later, the 16S rRNA sequences were submitted to NCBI and the GenBank accession number was assigned by NCBI (Table 2). The tree was built by the sum of branch length: 18.25543457 for PYI2, and 0.01185045 for YPI2. The phylogenetic tree between the 10-nucleotide sequences of all strains was created out by using the $\mathrm{NJ}$ algorithm (Fig 1). Our results were in consistent with other similar studies . The strain like Nocardia sp. NRRL 5646, Variovorax Ibu-1, Sphingomonas Ibu-2, Patulibacter sp. 111, and Bacillus thuringiensis B1 (2015b) were identified in previous IBU degradation studies (Chen and Rosazza 1994; Li and Rosazza 1997; Murdoch and Hay 2005b, 2013; Almeida et al. 2013; Marchlewicz et al. 2017b; Salgado et al. 2020).

\section{Optimization studies and statistical analysis of the degradation of IBU}

To analyze the best physical condition for the degradation of IBU mediated by the strains PYI2, and YPI2. The conditions was optimized with parameters of A: $\mathrm{pH}(3-10), \mathrm{B}$ : Temperature $\left(10-60^{\circ} \mathrm{C}\right), \mathrm{C}$ : Agitation speed $(50-280 \mathrm{rpm})$, and D: Concentration on IBU (0.25-30 mg/L). The BBD model generated the matrix of 29 experiments (Table 3 ) using a randomized subtype under the response surface study. The central composite design with a quadratic design model with no blocks was used to generate this matrix. The experiments were performed in the laboratory according to the designed matrix. The IBU degradation percentage was entered into the matrix and further processed with BBD-quadratic model.

ANOVA analysis has been performed with BBD-quadratic model for the degradation of IBU by PYI2 and YPI2 strains. The model was significant with the value to the sum of squares of 15868.17 and 5573.39 , degree of freedom (df) of 14 for each, mean square of 1133.44 and 398.10 , F-value of 14.16 , and 2.55 respectively, and p-values of < 0.0001 and 0.0451, respectively reported for thease strains (Supplementary Table S1 and S2). Subsequently ANOVA analysis, has been performed based on final equation for actual factor. Further, the report was generated based on the graph between the predicted value wrt actual values having a residual difference (Fig 2). The contour plots and 3D plots has been generated between two parameters viz. time vs\% degradation of IBU( represented as $A B v s \%$ degradation). Similarly, the contour plots, and 3D-plots were used for the analysis of all other parameters. Finally, the optimal values for the parameters. viz. $\mathrm{pH}$, temperature, agitation speed, and amount of IBU were reorted for PYI2 at $6.9,42^{\circ} \mathrm{C}, 240 \mathrm{rpm}, 1.4 \mathrm{mg} / \mathrm{L}$ and $\mathrm{YPI} 2$ at $5.8,32^{\circ} \mathrm{C}, 100$ $\mathrm{rpm}$, and $0.8 \mathrm{mg} / \mathrm{L}$, respectively, optimized by the software. The modeling and optimization study for the degradation of pharmaceutical acetaminophen, their kinetic analysis and modeling had indicated that, physical conditions viz. pH,temperature, rpm, had considerable effect on biodegradation (Chopra and Kumar 2020b).

In the previous studies, IBU-degrading microbe Novospingobium and Pseudomonas has been isolated from IBU-rich sediments and they can degrade 400 and $300 \mu \mathrm{M}$ of IBU in 3 and 8 days, respectively (Rutere et al. 2020). Sphingobium yanoikuyae can remove IBU/ 80 days (Balciunas et al., 2020). There is little information available about Ibuprofen metabolization by microorganisms. Though, some microbial strains have the capability to produce hydroxyl-ibuprofen and carboxylated-ibuprofen during degradation (Hanlon et al. 1994; Zwiener et al. 2002; Quintana et al. 2005; Marco-Urrea et al. 2010b; Salgado et al. 2020). The metabolic pathway of IBU have been determined in Sphingomonas Ibu-2 (Murdoch and Hay 2013, 2015).

\section{Kinetic study of IBU degrading strains}


The IBU degradation data, growth of bacteria, and biomass data has been subjected to Haldane's growth model in Origin 2017 software. This model suggested that the specific growth rate $(\mu)$ for the strains PYI2 and YPI2 was 14.2 , and $4.8 \mathrm{mg} / \mathrm{L}$, respectively. Further, the $\mu_{\max }$ and half-saturation constant were determined (Table 4).

\section{Identification of metabolites and pathways for IBU degradation}

The intermediate produced during biodegradation of IBU has been identified by analysis of GC/MS chromatogram. The peaks obtained in the chromatogram of the standard compound from the degraded samples was analyzed. The peaks in the chromatogram were resulting from the IBU mineralization observed during cell lysis. The comparison of chromatogram peaks has been done with the standard chromatogram peaks (without IBU and with bacteria) and the standard peak of IBU. The standard IBU retention time was at 15.738 with 99.69 area cover. The possible intermediate compounds were those metabolites that were not detected in the standard chromatogram. Moreover, the silicon-bearing molecule present in IBU was simplifying the identification, such compounds were not present in media This protocol suggested that 4 metabolites for IBUmainly hydroxyl-ibuprofen, 2- (4-hydroxyphenyl-) propionic acid, 1,4hydroquinone, and 2-hydroxy-1,4-quinol were identified with the retention time of 14.987, 15.654, 11.765, and 10.827, respectively. Afterwards, the massspectroscopy (MS) chart was used to detect the compound structure and molecular weight. Thishas suggested that the compound hydroxyl-ibuprofen, 2- (4hydroxyphenyl-) propionic acid, 1,4-hydroquinone, and 2-hydroxy-1,4-quinol have a molecular weight of 222, 166, 110, and 124 g/mol, respectively (Table 5). Joss et al., (2006) has been observed, that biodegradation models used for first order kinetic equations for the drug compound. The Monod-based kinetic equation and models used in many other drug biodegradation of PPCPs observed (Chopra and Kumar, 2020b, 2020c).

Finally, the prediction of degradation pathway has been done, based on GC-MS data and the literature available intended for degradation of IBU. Further, the compounds were confirmed by comparing it with the database of PubChem (https://pubch em.ncbi.n/m.nih.gov/). Compounds like hydroxyl-ibuprofen, 2- (4hydroxyphenyl-) propionic acid, 1,4-hydroquinone, and 2-hydroxy-1,4-quinol, were suggested based on the analysis of GC-MS chromatogram . In this wa,y metabolic pathway was predicted. PathPred deployed for the confirmation of the metabolic pathway. The instigation of IBU metabolism of occurred by the catabolic pathway and transforming IBU into hydroxyl-ibuprofen, 2- (4-hydroxyphenyl-) propionic acid, 1,4-hydroquinone, and 2-hydroxy-1,4-quinol, asdentified during GC-MS analysis and PathPred (Fig. 3).

The fungal Nocardiacan degrade it into carboxylic acid, further into alcohol, and acetylate(Chen and Rosazza 1994). IBU is further transformed into isobutyl catechol, due to cleavage of estradiol ring Patulibactersp. strain I11 has showed the involvement of enzymes in hydrolysis by ibuprofen (Almeida et al. 2013). Patulibacter medicamentivorans under aerobic conditions degraded IBU into two main intermediates, viz.2-phenylpropanoid acid and isobutyl benzene(Salgado et al. 2020). IBUs has been cleaved by enzyme estradiol dioxygenase to form 5-formyl-2-hydroxy-7-methylocta-2,4-dienoic acid by Bacillus thuringiensis B1 (2015b) (Marchlewicz et al. 2017a). The most important intermediate metabolite formed during IBU cleavage was hydroxylated with the isopropyl chain of ibuprofen 1 and 2-hydroxy-ibuprofen and the final metabolite generated was 1,2-dihydroxy-ibuprofen hydroxylation and carboxylated derivatives was common in microbial metabolism (Zwiener et al. 2002; Rodil et al. 2012). The decline started with 1,4-hydroquinone and another with 2hydroxyquinol. 1,4-Hydroquinone were e product of acyl-CoA synthase/thiolase activity and can be further converted to 2-hydroxy-1,4-quinol by hydroquinone monooxygenase enzyme. Furthermore, hydroxyquinol-1,2-dioxygenase activity was seen after incorporation with ibuprofen, due to the presence of glucose andthe enzyme was completely inactive. Enzyme hydroxyquinol 1,2-dioxygenase binds to 2-hydroxy-1,4-quinol and is involved in ortho-cleavage of this compound to 3-hydroxylase, and cis-muconic acid. During the biodegradation of IBU by Nocardia sp.NRRL 5646, two major metabolites, nitrophenol, and ibprophenol acetatewere generated. Withthe passage of time, these metabolites has been further metabolized by bacteria (Chen and Rosazza 1994). Murdoch and Hay $(2005,2013)$ characterized the best-known IBU degradation pathway in Sphingomonas Ibu-2 strain of bacteria, and this can use IBU as the sole source of carbon and energy. They also identified five gene clusters (Ipf ABDEF) involved in IBU mineralization. The ipf A and ipf B genes were encoded for two dioxygenase subunits. The ipf $D$ gene was encoded as an enzyme that removes/ads acylacyl-CoA synthetase groups. The Ipf $F$ was encoded by the coenzyme-A ligase gene. And finally, the function of the ipf $\mathrm{E}$ gene has not been explained. The degradation began with the degradation by Ibu-2 strain by coenzyme A. This enzyme has been involved in the removal of propionic acid chain, and further, reaction with oxygen resulted in the formation of isobutyl catechol. This compound has been susceptible to oxygen degradation(Murdoch and Hay 2013).

\section{Conclusions}

The bacterial strains reported in this study viz. Citrobacter PYI2 and YPI2 can degrade IBU in batch culture. The optimal pH for the growth for PYI2 and YPI2 was 6.9 and 5.8 , and the optimal temperature was at $42^{\circ} \mathrm{C}$ and $32^{\circ} \mathrm{C}$, respectively, re[orted for both of these strains. Haldane's growth kinetics had suggested that the specific growth rate for PYI2 and YPI2 was 14.2, and $4.8 \mathrm{mg} / \mathrm{L}$, respectively. The GC-MS analysis suggested that hydroxyl-ibuprofen, 2- (4hydroxyphenyl-) propionic acid, 1,4-hydroquinone, and 2-hydroxy-1,4-quinol were the main metabolites produced during degradation. Therefore, future research in this direction has the potential to analyze genes and sequences involved in IBU degradation, which to enhanced degradation and adaptation of strains will be elucidated.

\section{Declarations}

\section{Funding.}

There is no external funding received to carry out this research. The authors wish to thank the Department of Biotechnology, DCRUST Murthal Sonipat India, for providing the necessary facilities to carry out this research.

\section{Conflicts of interest/Competing interests.}


The authors declare there are no conflicts of interest/competing interests.

\section{Ethics approval.}

Not applicable.

\section{Consent to participate.}

Both authors were involved in the manuscript.

\section{Consent for publication.}

The authors have consent for the publication and approved the final draft of the manuscript.

\section{Availability of data and material:}

The 16S rRNA sequence data of the two IBU degrading Citrobacter freundii strain PYI-2 and and Citrobacter portucalensis strain YPI-2, was deposited to NCBI GenBank with accession number(s), MT039504 and MN74433, respectively.

\section{Code availability:}

Not applicable

\section{Compliance with ethical standards}

\section{Ethical approval for research involving human participants and/or animals.}

Not applicable

\section{Informed consent has been provided.}

Not applicable, as this study does not involve any human/animal study.

\section{Acknowledgments}

The authors acknowledge the sample analysis DNA sequencing at Eurofins Genomics India Pvt Ltd, Advanced Instrumentation Research Facility (AIRF), JNU New Delhi, India for GC-MS analysis. The author, S.Chopra wishes to thank UGC New Delhi India, for providing a research assistantship in the form of an RGNF fellowship. The authors are thankful to the Department of Biotechnology, DCR University of Science and Technology for providing the necessary facilities to conduct this study.

\section{References}

1. Aaij C, Borst P (1972) The gel electrophoresis of DNA. Biochim Biophys Acta (BBA)-Nucleic Acids Protein Synth 269:192-200

2. Alben KT (2002) Books and Software: Design, analyze, and optimize with Design-Expert

3. Almeida B, Kjeldal H, Lolas I, et al (2013) Quantitative proteomic analysis of ibuprofen-degrading Patulibacter sp. strain I11. Biodegradation 24:615-630. doi: 10.1007/s10532-012-9610-5

4. Ashton AR, Burnell JN, Hatch MD, et al (1997) Altschul SF, Madden TL, Schäffer AA, Zhang J, Zhang Z, Miller W \& Lipman DJ (1997). Nucl Acids Res 25:3389-3402

5. Balciunas EM, Kappelmeyer U, Harms H, Heipieper HJ (2020) Increasing ibuprofen degradation in constructed wetlands by bioaugmentation with gravel containing biofilms of an ibuprofen-degrading Sphingobium yanoikuyae. Eng Life Sci 20:160-167. doi: https://doi.org/10.1002/elsc.201900097

6. Barbosa MO, Moreira NFF, Ribeiro AR, et al (2016) Occurrence and removal of organic micropollutants: An overview of the watch list of EU Decision 2015/495. Water Res 94:257-279. doi: https://doi.org/10.1016/j.watres.2016.02.047

7. Chandra R, Ghosh A, Jain RK, Singh S (2006) Isolation and characterization of two potential pentachlorophenol degrading aerobic bacteria from pulp paper effluent sludge. J Gen Appl Microbiol 52:125-130

8. Chen Y, Rosazza JPN (1994) Microbial Transformation of Ibuprofen by a \&lt;em\&gt;Nocardia\&lt;/em\&gt; Species. Appl Environ Microbiol 60:1292 LP 1296 
9. Chopra, S., Kumar D., 2020a. Ibuprofen as an emerging organic contaminant in environment, distribution and remediation. Heliyon, 6, e04087. doi: 10.1016/j.heliyon.2020.e04087

10. Chopra, S., Kumar, D., 2020b. Characterization, optimization and kinetics study of acetaminophen degradation by Bacillus drentensis strain S1 and waste water degradation analysis. Bioresour. Bioprocess. 7. https://doi.org/10.1186/s40643-020-0297-x

11. Chopra, S., Kumar, D., 2020c. Characterization, optimization and kinetic study of diclofenac degradation by novel bacterial strains and their synthetic consortia. Bioremediation Journal 24(12):1-21DOI:10.1080/10889868.2020.1793723

12. Daughton CG, Ternes TA (1999) Pharmaceuticals and personal care products in the environment: agents of subtle change? Environ Health Perspect 107:907-938. doi: 10.1289/ehp.99107s6907

13. Deblonde T, Cossu-Leguille C, Hartemann P (2011) Emerging pollutants in wastewater: a review of the literature. Int J Hyg Environ Health $214: 442-448$

14. Deschenes LA, of Texas A (2000) Origin 6.0: Scientific Data Analysis and Graphing Software Origin Lab Corporation (formerly Microcal Software, Inc.). Web site: www. originlab. com. Commercial price: 595.Academicprice: 446

15. Ellis JB (2006) Pharmaceutical and personal care products (PPCPs) in urban receiving waters. Environ Pollut 144:184-189

16. Farré M la, Pérez S, Kantiani L (2008) Fate and toxicity of emerging pollutants, their metabolites and transformation products in the aquatic environment. TrAC Trends Anal Chem 27:991-1007. doi: 10.1016/J.TRAC.2008.09.010

17. Felsenstein $\mathrm{J}$ (1985) Confidence limits on phylogenies: an approach using the bootstrap. Evolution (N Y) 39:783-791

18. Fent K, Weston AA, Caminada D (2006) Ecotoxicology of human pharmaceuticals. Aquat Toxicol 76:122-159. doi: 10.1016/J.AQUATOX.2005.09.009

19. Gorashi NE, Tripathi M, Kalia V, Gujar GT (2014) Identification and characterization of the Sudanese Bacillus thuringiensis and related bacterial strains for their efficacy against Helicoverpa armigera and Tribolium castaneum

20. Halden RU, Halden BG, Dwyer DF (1997) A kinetic analysis of dioxin degradation in bioaugmented soils. Abstr Annu Meet Am Soc Microbiol, poster Q-381

21. Hanlon GW, Kooloobandi A, Hutt AJ (1994) Microbial metabolism of 2-arylpropionic acids: effect of environment on the metabolism of ibuprofen by Verticillium lecanii. J Appl Bacteriol 76:442-447. doi: 10.1111/j.1365-2672.1994.tb01100.x

22. Hoffmann G, Aramaki S, Blum-Hoffmann E, et al (1989) Quantitative analysis for organic acids in biological samples: batch isolation followed by gas chromatographic-mass spectrometric analysis. Clin Chem 35:587-595

23. Hucker GJ, Conn HJ (1923) Methods of Gram staining

24. Jahanshahi M, Sanati MH, Babaei Z (2008) Optimization of parameters for the fabrication of gelatin nanoparticles by the Taguchi robust design method. J Appl Stat 35:1345-1353

25. Jardim WF, Moraes SG, Takiyama MMK (1997) Photocatalytic degradation of aromatic chlorinated compounds using TiO2: Toxicity of intermediates. Water Res 31:1728-1732. doi: 10.1016/S0043-1354(96)00349-1

26. Joss A, Zabczynski S, Göbel A, et al (2006) Biological degradation of pharmaceuticals in municipal wastewater treatment: Proposing a classification scheme. Water Res 40:1686-1696. doi: 10.1016/J.WATRES.2006.02.014

27. Jurado A, Vàzquez-Suñé E, Carrera J, et al (2012) Emerging organic contaminants in groundwater in Spain: A review of sources, recent occurrence and fate in a European context. Sci Total Environ 440:82-94. doi: 10.1016/J.SCITOTENV.2012.08.029

28. Kesur BR, Salunkhe VR, Magdum CS (2012) Development and validation of UV spectrophotometric method for simultaneous estimation of ibuprofen and famotidine in bulk and formulated tablet dosage form. Int J Pharm Pharm Sci 4:271-274

29. Kimura M (1980) A simple method for estimating evolutionary rates of base substitutions through comparative studies of nucleotide sequences. $J$ Mol Evol 16:111-120

30. Kumar S, Stecher G, Tamura K (2016) MEGA7: Molecular Evolutionary Genetics Analysis Version 7.0 for Bigger Datasets. Mol Biol Evol 33:1870-1874. doi: 10.1093/molbev/msw054

31. Li T, Rosazza JP (1997) Purification, characterization, and properties of an aryl aldehyde oxidoreductase from Nocardia sp. strain NRRL 5646. J Bacteriol 179:3482 LP - 3487. doi: 10.1128/jb.179.11.3482-3487.1997

32. Marchlewicz A, Guzik U, Hupert-Kocurek K, et al (2017a) Toxicity and biodegradation of ibuprofen by Bacillus thuringiensis B1(2015b). Environ Sci Pollut Res 24:7572-7584. doi: 10.1007/s11356-017-8372-3

33. Marchlewicz A, Guzik U, Smułek W, Wojcieszyńska D (2017b) Exploring the degradation of ibuprofen by bacillus thuringiensis B1(2015b): The new pathway and factors affecting degradation. Molecules 22:. doi: 10.3390/molecules22101676

34. Marchlewicz A, Guzik U, Wojcieszyńska D (2015) Over-the-Counter Monocyclic Non-Steroidal Anti-Inflammatory Drugs in Environment - Sources, Risks, Biodegradation. Water Air Soil Pollut 226:. doi: 10.1007/s11270-015-2622-0

35. Marco-Urrea E, Pérez-Trujillo M, Blánquez P, et al (2010a) Biodegradation of the analgesic naproxen by Trametes versicolor and identification of intermediates using HPLC-DAD-MS and NMR. Bioresour Technol 101:2159-2166. doi: 10.1016/J.BIORTECH.2009.11.019

36. Marco-Urrea E, Pérez-Trujillo M, Cruz-Morató C, et al (2010b) White-rot fungus-mediated degradation of the analgesic ketoprofen and identification of intermediates by HPLC-DAD-MS and NMR. Chemosphere 78:474-481. doi: https://doi.org/10.1016/j.chemosphere.2009.10.009

37. Murdoch RW, Hay AG (2013) Genetic and chemical characterization of ibuprofen degradation by Sphingomonas Ibu-2. Microbiology 159:621-632. doi: $10.1099 /$ mic.0.062273-0

38. Murdoch RW, Hay AG (2005a) Formation of catechols via removal of acid side chains from ibuprofen and related aromatic acids. Appl Environ Microbiol 71:6121-6125. doi: 10.1128/AEM.71.10.6121-6125.2005 
39. Murdoch RW, Hay AG (2015) The biotransformation of ibuprofen to trihydroxyibuprofen in activated sludge and by Variovorax Ibu-1. Biodegradation 26:105-113. doi: 10.1007/s10532-015-9719-4

40. Murdoch RW, Hay AG (2005b) Formation of catechols via removal of acid side chains from ibuprofen and related aromatic acids. Appl Environ Microbiol 71:6121-6125. doi: 10.1128/AEM.71.10.6121-6125.2005

41. Murray KE, Thomas SM, Bodour AA (2010) Prioritizing research for trace pollutants and emerging contaminants in the freshwater environment. Environ Pollut 158:3462-3471

42. Muthukumar M, Mohan D, Rajendran M (2003) Optimization of mix proportions of mineral aggregates using Box Behnken design of experiments. Cem Concr Compos 25:751-758

43. Norris JR, Ribbons DW (1972) Methods in microbiology. Academic Press

44. Ogata H, Goto S, Fujibuchi W, Kanehisa M (1998) Computation with the KEGG pathway database. Biosystems 47:119-128

45. Onesios KM, Yu JT, Bouwer EJ (2009) Biodegradation and removal of pharmaceuticals and personal care products in treatment systems: a review. Biodegradation 20:441-466. doi: 10.1007/s10532-008-9237-8

46. Pal A, Gin KY-H, Lin AY-C, Reinhard M (2010) Impacts of emerging organic contaminants on freshwater resources: review of recent occurrences, sources, fate and effects. Sci Total Environ 408:6062-6069

47. Panikov NS (1995) Microbial growth kinetics. Springer Science \& Business Media

48. Peters NE, Meybeck M (2000) Water quality degradation effects on freshwater availability: impacts of human activities. Water Int 25:185-193

49. Quintana JB, Weiss S, Reemtsma T (2005) Pathways and metabolites of microbial degradation of selected acidic pharmaceutical and their occurrence in municipal wastewater treated by a membrane bioreactor. Water Res 39:2654-2664. doi: 10.1016/J.WATRES.2005.04.068

50. Rastogi A, Tiwari MK, Ghangrekar MM (2021) A review on environmental occurrence, toxicity and microbial degradation of Non-Steroidal AntiInflammatory Drugs (NSAIDs). J Environ Manage 300:113694. doi: https://doi.org/10.1016/j.jenvman.2021.113694

51. Rodil R, Quintana JB, Concha-Graña E, et al (2012) Emerging pollutants in sewage, surface and drinking water in Galicia (NW Spain). Chemosphere 86:1040-1049. doi: https://doi.org/10.1016/j.chemosphere.2011.11.053

52. Rutere C, Knoop K, Posselt M, et al (2020) Ibuprofen Degradation and Associated Bacterial Communities in Hyporheic Zone Sediments. Microorganisms 8.: doi: $10.3390 /$ microorganisms 8081245

53. Salgado R, Brito D, Noronha JP, et al (2020) Metabolite identification of ibuprofen biodegradation by Patulibacter medicamentivorans under aerobic conditions. Environ Technol (United Kingdom) 41:450-465. doi: 10.1080/09593330.2018.1502362

54. Santos LH, Araújo AN, Fachini A, et al (2010) Ecotoxicological aspects related to the presence of pharmaceuticals in the aquatic environment. J Hazard Mater 175:45-95

55. Sharma K, Kaushik G, Thotakura N, et al (2019) Fate of ibuprofen under optimized batch biodegradation experiments using Micrococcus yunnanensis isolated from pharmaceutical sludge. Int J Environ Sci Technol 16:8315-8328. doi: 10.1007/s13762-019-02400-9

56. Smith K, Diggle MA, Clarke SC (2003) Comparison of commercial DNA extraction kits for extraction of bacterial genomic DNA from whole-blood samples. J Clin Microbiol 41:2440-2443

57. Swift HF (1921) Preservation of stock cultures of bacteria by freezing and drying. J Exp Med 33:69-75

58. Thompson JD, Higgins DG, Gibson TJ (1994) CLUSTAL W: improving the sensitivity of progressive multiple sequence alignment through sequence weighting, position-specific gap penalties and weight matrix choice. Nucleic Acids Res 22:4673-4680

59. Wallis Y, Morrell N (2011) Automated DNA sequencing. In: PCR Mutation Detection Protocols. Springer, pp 173-185

60. Wang Y, Wang Q, Wang Y, et al (2017) Statistical optimization for the production of recombinant cold-adapted superoxide dismutase in E. coli using response surface methodology. Bioengineered 8:693-699. doi: 10.1080/21655979.2017.1303589

61. Wilson K (2001) Preparation of Genomic DNA from Bacteria. Curr Protoc Mol Biol 56:2.4.1-2.4.5. doi: 10.1002/0471142727.mb0204s56

62. Zwiener C, Seeger S, Glauner T, Frimmel F (2002) Metabolites from the biodegradation of pharmaceutical residues of ibuprofen in biofilm reactors and batch experiments. Anal Bioanal Chem 372:569-575. doi: 10.1007/s00216-001-1210-x

\section{Tables}

Table 1

Biochemical characterization of IBU degrading bacterial strains.

\begin{tabular}{|c|c|c|c|c|c|c|c|c|c|c|c|c|c|c|}
\hline Strain & Malonate & $\begin{array}{l}\text { Voges } \\
\text { Proskauer's }\end{array}$ & Citrate & ONPG & $\begin{array}{l}\text { Nitrate } \\
\text { reduction }\end{array}$ & & lase & Arginine & & Sucrose & Mannitol & Glucose & Arabinose & Trel \\
\hline PYI2 & - & - & + & + & + & + & vari & ble & + & + & + & + & + & \\
\hline YPI2 & - & - & + & + & + & + & vari & able & + & + & + & + & + & \\
\hline
\end{tabular}

Table 2

Page 9/12 
Identified strains having the potential to degrade NSAIDs with their accession number provided by NCBI.

\begin{tabular}{|lll|}
\hline Strain & Accession no & Identified Strain \\
\hline PYI2 & MT039504 & Citrobacter freundii strain PYI-2 \\
\hline YPI2 & MN744335 & Citrobacter portucalensis strain YPI-2 \\
\hline
\end{tabular}

Table 3

The BBD matrix for the IBU degradation by the strain PYI2, and YPI2.

\begin{tabular}{|c|c|c|c|c|c|c|c|c|}
\hline \multirow{3}{*}{ Run } & \multirow{3}{*}{$\begin{array}{l}\text { Factor } 1 \\
\text { A: pH }\end{array}$} & \multirow{3}{*}{$\begin{array}{l}\text { Factor } 2 \\
\text { B: Temperature } \\
{ }^{\circ} \mathrm{C}\end{array}$} & \multirow{3}{*}{$\begin{array}{l}\text { Factor } 3 \\
\text { C: Agitation Speed } \\
\text { rpm }\end{array}$} & \multirow{3}{*}{$\begin{array}{l}\text { Factor } 4 \\
\text { D: Amount of Ibuprofen } \\
\mathrm{mg} / \mathrm{L}\end{array}$} & \multirow{2}{*}{\multicolumn{2}{|c|}{$\begin{array}{l}\text { Response } 1 \\
\text { \% degradation of IBU by PYI2 }\end{array}$}} & \multirow{2}{*}{\multicolumn{2}{|c|}{$\begin{array}{l}\text { Response } 2 \\
\text { \% degradation of IBU by YPI2 }\end{array}$}} \\
\hline & & & & & & & & \\
\hline & & & & & Experimental & Predicted & Experimental & Predicted \\
\hline 1 & 5 & 50 & 250 & 20 & 45 & 49.29 & 15 & 23.80 \\
\hline 2 & 9 & 50 & 80 & 0.5 & 45 & 46.82 & 19 & 21.03 \\
\hline 3 & 3 & 30 & 165 & 10.25 & 0 & -4.36 & 0 & 3.81 \\
\hline 4 & 9 & 10 & 80 & 20 & 52 & 46.73 & 23 & 16.52 \\
\hline 5 & 5 & 10 & 80 & 20 & 42 & 49.60 & 26 & 28.06 \\
\hline 6 & 5 & 50 & 80 & 20 & 43 & 40.08 & 28 & 32.36 \\
\hline 7 & 9 & 10 & 80 & 0.5 & 57 & 48.84 & 32 & 23.73 \\
\hline 8 & 9 & 50 & 250 & 0.5 & 64 & 52.53 & 15 & 13.46 \\
\hline 9 & 9 & 50 & 80 & 20 & 37 & 34.45 & 12 & 14.57 \\
\hline 10 & 9 & 10 & 250 & 0.5 & 38 & 40.81 & 26 & 23.91 \\
\hline 11 & 7 & 30 & 165 & 0.25 & 78 & 91.56 & 27 & 49.53 \\
\hline 12 & 5 & 10 & 250 & 20 & 47 & 45.07 & 27 & 27.25 \\
\hline 13 & 7 & 30 & 165 & 10.25 & 82 & 77.78 & 58 & 44.78 \\
\hline 14 & 5 & 50 & 80 & 0.5 & 68 & 61.69 & 56 & 42.07 \\
\hline 15 & 7 & 30 & 280 & 10.25 & 92 & 92.75 & 56 & 37.61 \\
\hline 16 & 7 & 30 & 165 & 10.25 & 87 & 77.78 & 45 & 44.78 \\
\hline 17 & 7 & 30 & 165 & 30 & 89 & 89.41 & 58 & 49.50 \\
\hline 18 & 9 & 50 & 250 & 20 & 39 & 35.92 & 15 & 14.76 \\
\hline 19 & 5 & 50 & 250 & 0.5 & 70 & 75.16 & 17 & 25.76 \\
\hline 20 & 10 & 30 & 165 & 10.25 & 0 & 14.84 & 0 & 1.80 \\
\hline 21 & 7 & 30 & 165 & 10.25 & 80 & 77.78 & 53 & 44.78 \\
\hline 22 & 5 & 10 & 80 & 0.5 & 58 & 60.96 & 36 & 38.52 \\
\hline 23 & 9 & 10 & 250 & 20 & 32 & 34.44 & 10 & 24.45 \\
\hline 24 & 7 & 30 & 165 & 10.25 & 83 & 77.78 & 46 & 44.78 \\
\hline 25 & 7 & 10 & 165 & 10.25 & 60 & 57.86 & 40 & 41.77 \\
\hline 26 & 5 & 10 & 250 & 0.5 & 62 & 60.68 & 32 & 29.95 \\
\hline 27 & 7 & 60 & 165 & 10.25 & 27 & 35.03 & 38 & 32.24 \\
\hline 28 & 7 & 30 & 165 & 10.25 & 80 & 77.78 & 35 & 44.78 \\
\hline 29 & 7 & 30 & 50 & 10.25 & 84 & 91.95 & 31 & 43.27 \\
\hline
\end{tabular}

Table 4

The $\mu, \mu_{\max }$ and Ks for the degradation of IBU.

Page $10 / 12$ 


\begin{tabular}{|llll|}
\hline Strain & Specific growth rate & Maximum specific growth rates & $\begin{array}{l}\text { Half-saturation } \\
\text { Constant }\end{array}$ \\
& $(\mathrm{mg} / \mathrm{L})$ & $\mu_{\max }\left(\mathrm{h}^{-1}\right)$ & $\mathrm{K}_{\mathrm{s}}(\mathrm{mg} / \mathrm{L})$ \\
PYI2 & 14.2 & 0.175 & 4.6 \\
\hline YPI2 & 4.8 & 0.080 & 4.8 \\
\hline
\end{tabular}

Table 5

Major metabolites identified during degradation of IBU by GC/MS.

\begin{tabular}{|llll|}
\hline S.No. & Retention time & Compound & MWt \\
\hline 1. & 14.987 & Hydroxyibuprofen & 222 \\
\hline 2. & 15.654 & 2-(4-hydroxyphenyl-) propionic acid & 166 \\
\hline 3. & 11.765 & 1,4-hydroquinone & 110 \\
\hline 4. & 10.827 & 2-hydroxy-1,4-quinol & 124 \\
\hline
\end{tabular}

\section{Figures}

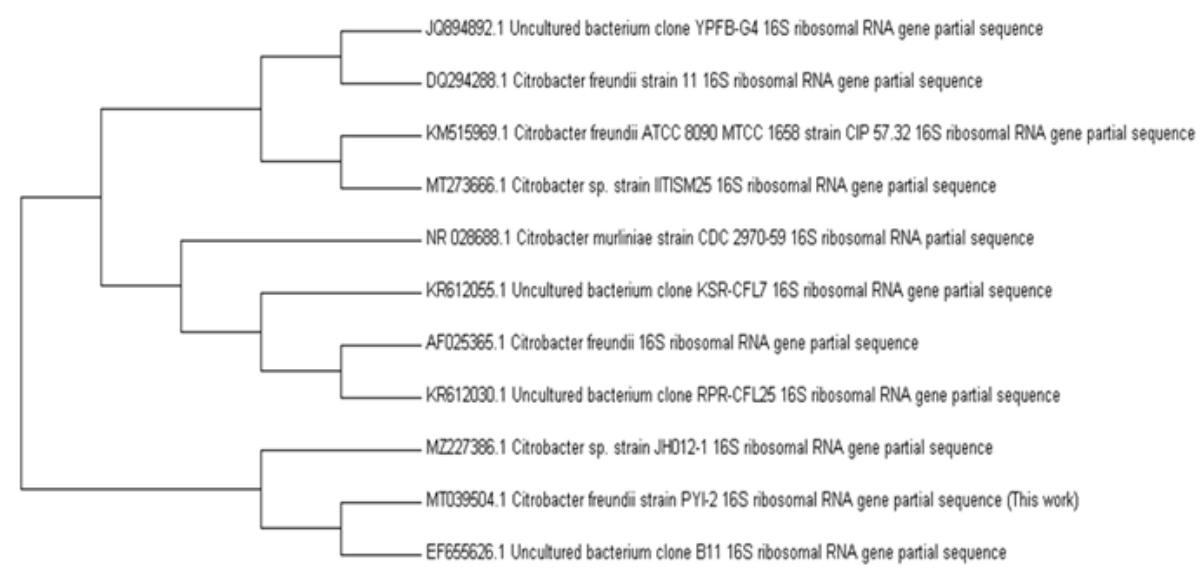

a)

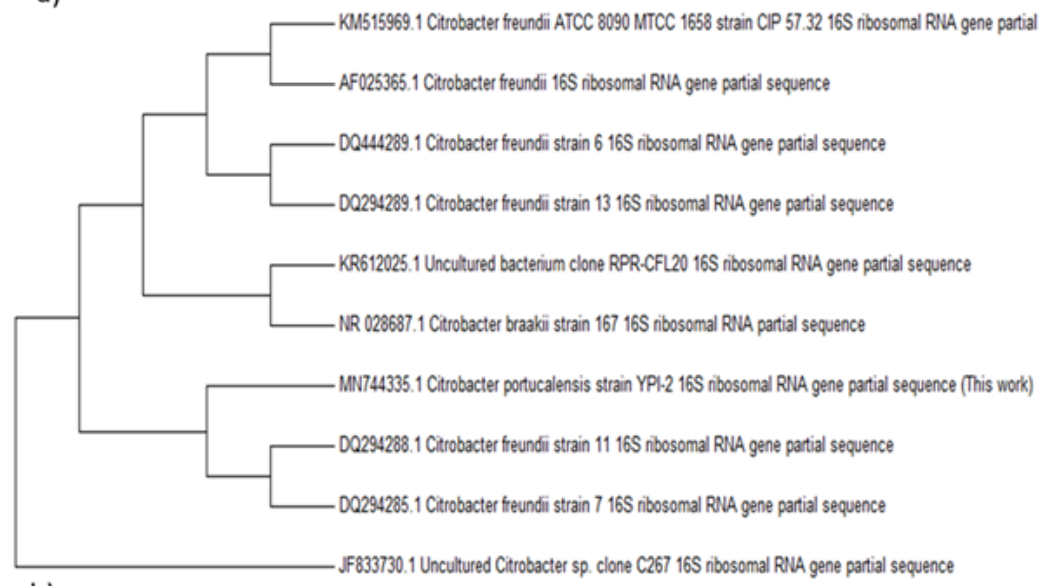

b)

Figure 1

Phylogenetic tree for the IBU degrading strains by strains., a) PYI2, b) YPI2. 

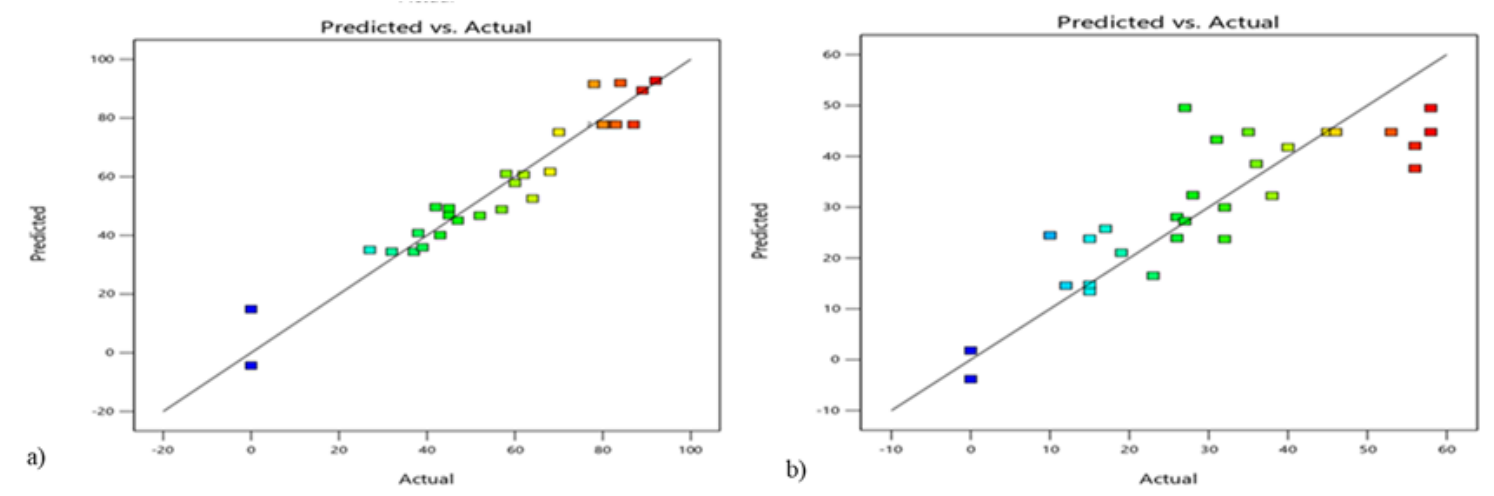

Figure 2

The graph between the residual and predicted values of strains., a) PYI2, and b) YPI2.

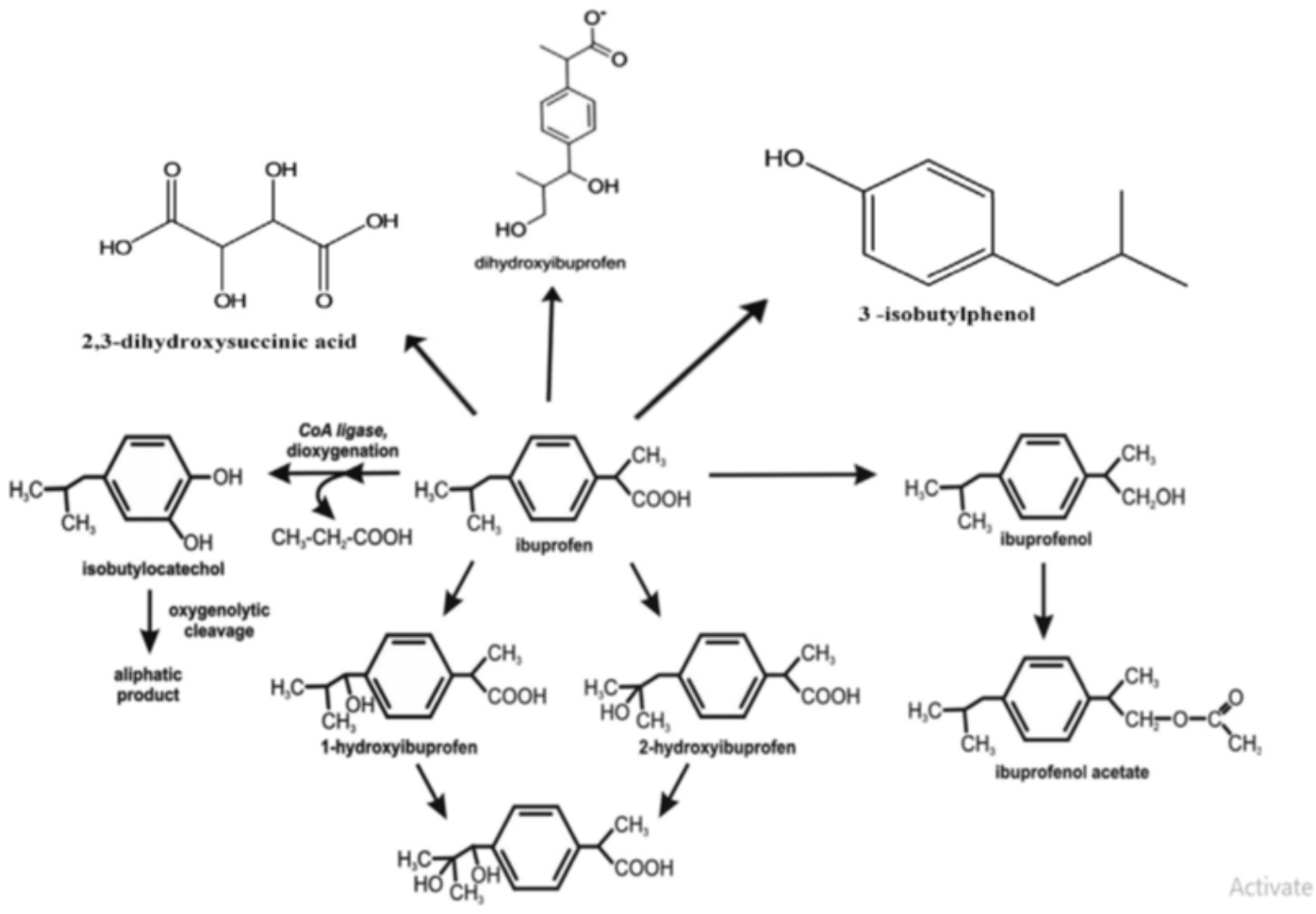

Figure 3

A predicted metabolic pathway for degradation of IBU.

\section{Supplementary Files}

This is a list of supplementary files associated with this preprint. Click to download.

- supplementaryfilestables.docx 